University of Warwick institutional repository: http://go.warwick.ac.uk/wrap This paper is made available online in accordance with publisher policies. Please scroll down to view the document itself. Please refer to the repository record for this item and our policy information available from the repository home page for further information.

To see the final version of this paper please visit the publisher's website. Access to the published version may require a subscription.

Author(s): Williamson, Mark; Dehnen-Schmutz, Katharina; Kühn, Ingolf; Hill, Mark; Klotz, Stefan; Milbau, Ann; Stout, Jane; Pyšek, Petr Article Title: The distribution of range sizes of native and alien plants in four European countries and the effects of residence time Year of publication: 2009

Link to published version: http://dx.doi.org/10.1111/j.14724642.2008.00528.x

Publisher statement: The definitive version is available at www.blackwell-synergy.com 
Williamson, M., Dehnen-Schmutz, K., Kühn, I., Hill, M., Klotz, S., Milbau, A., Stout, J., Pyšek, P. (2009) : The distribution of range sizes of native and alien plants in four European countries and the effects of residence time. Diversity and Distributions 15 : 158-166.

\section{The distribution of range sizes of native and alien plants in four European countries and the effects of residence time}

Short running title: Range sizes and residence time

Mark Williamson $^{1 *}$, Katharina Dehnen-Schmutz ${ }^{1,6}$, Ingolf Kühn ${ }^{2}$, Mark Hill ${ }^{3}$, Stefan Klotz $^{2}$, Ann Milbau ${ }^{4,7}$, Jane Stout ${ }^{4}$ and Petr Pyšek ${ }^{5}$

${ }^{1}$ Department of Biology, University of York, York, YO10 5DD, UK, ${ }^{2}$ Department Community Ecology, Helmholtz Centre for Environmental Research-UFZ, TheodorLieser-Str. 4, 06120 Halle, Germany, ${ }^{3}$ Biological Records Centre, Centre for Ecology and Hydrology, Monks Wood, Abbots Ripton, Huntingdon, PE28 2LS, England, ${ }^{4}$ School of Natural Sciences, Botany Building, Trinity College, Dublin 2, Ireland, ${ }^{5}$ Department of Invasion Ecology, Institute of Botany, Academy of Sciences of the Czech Republic, CZ-252 43, Průhonice, and Department of Ecology, Faculty of Science, Charles University Prague, CZ-128 01 Viničná 7, Praha 2, Czech Republic, ${ }^{6}$ Present address: Warwick HRI, University of Warwick, Wellesbourne, Warwick, CV35 9EF, UK, ${ }^{7}$ Present address: Climate Impacts Research Centre, Abisko Scientific Research Station, SE-98107 Abisko, Sweden

*Correspondence: Mark Williamson, Department of Biology, University of York, York, YO10 5DD, UK. E-mail: mw1@york.ac.uk

\section{(A) ABSTRACT}


Do the statistical distributions of range sizes of native and alien species differ? If so, is this because of residence time effects? And can such effects indicate an average time to a maximum? Here we examine these questions for higher plants in Ireland, Britain, Germany and the Czech Republic, the first two defined geographically, the last two politically. The areas vary from 79 to 357 thousand $\mathrm{km}^{2}$. The data are presence or absence in mapping units of $100 \mathrm{~km}^{2}$ (Ireland and Britain) or ca. $130 \mathrm{~km}^{2}$ (Germany and the Czech Republic). The current range sizes, in logits, are near normally distributed. Those of native plants are larger than those of naturalized neophytes (plants introduced since 1500 AD) and much larger than those of casual neophytes. Archaeophytes (introduced earlier) have range sizes slightly larger than natives, except in Ireland. Residence time, the time since an invasive species arrived in the wild at a certain place, affects range sizes. The relationships of the range of naturalized neophytes to residence time is effectively straight in all four places, showing no significant curvature or asymptote back to 1500, though there are few records between 1500 and 1800 . The relationships have an $\mathrm{r}^{2}$ of only about $10 \%$. Both regressions and reduced major axes can be used to estimate the time it takes for the range of a naturalized neophyte to reach a maximum. Most of the estimates indicate a time around 150 years but some a time of around 300 years. As most neophytes have been introduced in the last 150 years, these results mean that almost all naturalized neophytes are still expanding their ranges in Europe.

Keywords archaeophytes, Europe, native plants, neophyte spread, range size, residence time

\section{(A) INTRODUCTON}

Range size is an important and dynamic characteristic of a species. The statistical properties, such as means, of sets of range sizes reflect the distribution of biodiversity. 
The differences in range sizes between species has been studied for different taxonomic groups, different habitats, different biogeographic regions, by latitude, longitude, trophic group, body size, dispersal ability, abundance and genetic variation (Gaston, 2003). Surprisingly, the difference between alien and native species and between classes of aliens has scarcely been studied. Here we consider these comparisons for higher plants in four European areas, thereby controlling for most of the other comparisons that have been made.

It has become widely recognised that residence time, the time from the first record in the wild until now, is an important determinant of the present geographical range sizes of alien plants in the country in which they have escaped or been released (Rejmánek, 2000; Kühn \& Klotz, 2003; Wu et al., 2003; Castro et al., 2005; Hamilton et al., 2005; Pyšek \& Jarošík, 2005; Rejmánek et al., 2005; Lambdon \& Hulme, 2006; Essl, 2007; Wilson et al., 2007). Residence time is by no means the only determinant of range size (Kühn et al., 2004). Pyšek \& Jarošík (2005), for instance, found the proportion of the variance in range associated with residence time, $\mathrm{r}^{2}$, to vary in 15 examples from 4.1 to $39.6 \%$ with a median of $18.7 \%$. Cadotte et al. (2006), Richardson \& Pyšek (2006) and Pyšek \& Richardson (2007) have reviewed the known effects of residence time.

There are two implications from the importance of residence time that deserve more study. The first is that the ranges of alien plants are likely to be smaller on average than the ranges of natives because most aliens are likely to be still increasing their range. The second is that it should be possible to estimate how long it takes for the average range size of aliens to reach a maximum. There is little published evidence on these two implications. On the first, Williamson (1998) and Williamson and Gaston (1999) showed, both for all aliens and for naturalized aliens, that the range measured in hectads, $10 \mathrm{~km} \times 10 \mathrm{~km}$ grid squares, of alien plants in Britain is much smaller than the range of natives. On the second implication, Guo et al. (2006) show an approach to an asymptote in North America after about 400 years, and fitted an asymptote to their Eastern Asian data from 100 years; those latter data seem to us to be more complex than that, still increasing at 600 years residence time. In both cases 
they used quite large political units for determining range. Williamson (2002) showed that only eight out of thirty "interesting" (sic) British alien plants showed no significant increase between 1958 and 1988 and two of the eight are the only archaeophytes in the set. That indicates the time to reach maximum range in Britain is measured in centuries.

In Europe, there are data sets giving the range of native and alien plants measured in small mapping units of around $100 \mathrm{~km}^{2}$, and also information of the date at which aliens were introduced and found in the wild. Here we examine the three points above: the statistical distribution of range size for various categories of aliens and for natives, the importance of residence time in determining range and the time it takes for aliens, on average, to cease spreading. We use data from four European areas: from west to east, Ireland, Britain, Germany and the Czech Republic. The aim of this paper is to quantify those three points.

\section{(A) METHODS}

\section{(B) Data sets}

For each area we used a dataset containing information on the current distribution of native and alien plant species measured in number of mapping units. For Britain and Ireland, the size of the grid square is $10 \mathrm{~km} \times 10 \mathrm{~km}, 100 \mathrm{~km}^{2}$, a hectad (Williamson et al., 2006). In Germany and the Czech Republic units of 10' longitude $\times 6$ ' latitude (Schönfelder, 1999) are used, about $130 \mathrm{~km}^{2}$, varying from 118 to $140 \mathrm{~km}^{2}$ (Kühn et al., 2003). The status of species is either native or alien; aliens are either archaeophytes, introduced before $1500 \mathrm{AD}$, or neophytes, introduced later, and also either casual or naturalized (Pyšek et al., 2004). We have taken the status given in the data sets, but other workers might want to assign a few of the species differently. The distinction between casual and naturalized can be fuzzy (Williamson et al., 2005), as 
can be deciding which species are archaeophytes (Preston et al., 2004). Table 1 gives the number of species in different categories in each country in our data.

\section{(C) Irish data}

We used the 1987-1999 distributions from the CD of the New Atlas (Preston et al., 2002). Unlike the New Atlas we treated hybrid species with at least one alien parent as alien, following Pyšek et al. (2004). Some species are alien in Ireland but native in Britain and are called native in the text of the New Atlas though shown red (for alien) on the maps of Ireland. We have taken these as alien. We derived a list of Irish archaeophytes by taking all species that are naturalized in Ireland from the British archaeophyte list (Preston et al., 2004) and discuss in Williamson et al. (in press) the criteria used and the validity of this approach. Alien status and first record date were taken from Milbau \& Stout (2007). We only used neophyte species with a first record date (Table 1). The number of hectads is 1007 , the area about $84,000 \mathrm{~km}^{2}$.

\section{(C) British data}

As for Ireland, we used the 1987-1999 distributions from the CD of Preston et al. (2002). Species recorded as native in some hectads and alien in others were called natives. Archaeophytes are those in Preston et al. (2004). Information on the status of neophytes and the date of the first record were taken mainly from Hill et al. (2005) supplemented by Clement and Foster (1994). There are 2837 hectads in Britain, including the Isle of Man but not the Channel Islands; the area of Britain so defined is about $229,000 \mathrm{~km}^{2}$.

\section{(C) German data}

For ranges, we used the FLORKART data base (www.floraweb.de) maintained by the German Federal Agency for Nature Conservation for the German Network for 
Phytodiversity (Kühn et al. 2003) with records up to 2001. Status and the date of the first record come from the BIOLFLOR database (Klotz et al. 2002), http://www.biolflor.de/. The number of mapping units is 2995 , the area about 357,000 $\mathrm{km}^{2}$.

\section{(C) Czech data}

The status of alien species was taken from Pyšek et al. (2002). The number of mapping units recorded up to 2005 for both alien and native species was from a working database of the national flora held at the Department of Invasion Ecology, Institute of Botany, Průhonice, which is not publicly available. It was compiled using the national database of floristic literature FLDOK (Institute of Botany Průhonice), national floras (Hejný \& Slavík, (1988-1992); Slavík, (1995-2004); Kubát et al., (2002)) and atlases (Slavík, (1986-1990, 1998)) and also the primary literature (see Pyšek et al., 2002). We only used neophyte species with a first record date, 568 of them (Table 1) and natives for which there is a grid map, 799 out of 2750 . There are 682 mapping units and the area is about $79,000 \mathrm{~km}^{2}$.

\section{(B) Statistical points}

Our statistical work generally follows standard procedures (Sokal \& Rohlf, 1995) that need not be described here. Most of our calculations were done in R (R Development Core Team 2006) though some were done in Minitab 13. Four points perhaps need some explanation:

Logits. Following Williamson \& Gaston (1999), range size was transformed to $\operatorname{logits}$, which are $\log (p / q)$ where $p$ is the proportion of mapping units occupied out of the total available in the area and $q$ the proportion unoccupied. The totals are given above. Logits have the additional advantage that they produce comparisons of the proportion of the area occupied which is appropriate for our data as all four areas are 
in the European temperate zone with a range of habitats characteristic of that zone and of comparable sizes.

Normality testing. The Ryan-Joiner test (available in Minitab) looks at the probability that the correlation of the normit (i.e. normal scores) and the measure being studied is significantly different from unity, rather than from zero as in standard correlation tests. It is equivalent to the Shapiro-Wilks $W$ test, described fully in section 7.2.1.3 of NIST/SEMATECH (2006).

Loess curves. These are locally weighted scatterplot smoothers and are calculated as locally weighted polynomial regressions over a span of values. They can be thought of as a development of moving averages and are described fully in section 4.1.4.4 of NIST/SEMATECH (2006). The loess line can also be called a loess regression.

Reduced major axis (RMA). In the relationship of residence time and range, both the response and explanatory variables have errors. In ordinary least square (OLS, model I) regression the predictor variable is treated as precise and only the response variable is assumed to have error. We therefore also use a model II regression approach, the Reduced Major Axis (RMA), sometimes called the standard major axis, as the two variables are standardised, and the geometric mean regression, as the line is the geometric mean of the regressions of $x$ on $y$ and of $y$ on $x$ (Sokal \& Rohlf, 1995). The line is also the first principal component of a Principal Components Analysis of the correlation matrix of $x$ and $y$. The slope is given by the ratio of the standard deviations of the two variables with the sign of their correlation. This equals $b_{O L S} / r_{x y}$, where $b_{O L S}$ is the OLS slope and $r_{x y}$ the Pearson correlation coefficient. The RMA has the same s.e. and so $r^{2}$ as the OLS regression, but is necessarily steeper. We use both OLS and RMA to estimate the time needed for the average range size of neophytes to come to a maximum. We assume the maximum to be the average range size of natives. Our reasons for making this assumption use the results on current distribution and residence time and so are given after those results.

\section{(A) RESULTS}




\section{(B) Current distributions}

The distribution of range sizes by country and status is summarized in Fig. 1. The results of tests of normality for logits are given in Table 2; logarithmic and square root transformations and the raw data give unsatisfactory fits.

There are sixteen sets in Fig. 1 each of a different size (Table 1). A two-way ANOVA by country and status is therefore over different size sets but indicates that all statuses and all countries are significantly different and that there is significant interaction between them. The highly significant interactions make it easier to interpret a one-way ANOVA of all sixteen sets. Using Tukey comparisons from that to group together sets that are not significantly different produces five groups of sets (Table 3). All the sets in groups E (casuals) and D (Irish and German naturalized neophytes) are significantly different from all other sets. Groups A to $\mathrm{C}$ though form a continuum which was separated by making group A contain all sets not significantly different from the most widespread set (German archaeophytes) and group C all those not significantly different form the least widespread (British naturalized neophytes), leaving group B in the middle with its sets all not significantly different from each other but also, in some cases, not significantly different from some sets in either group A or group C.

These groupings confirm what can be seen in Fig. 1. Archaeophytes, other than in Ireland, are the most widespread and form group A. The next largest ranges are found in natives (group B), though German natives (in group C) are rather restricted. After those come naturalized neophytes, though the Czech and British (in group C) are significantly more widespread than the Irish and German (group D) and then, with much the smallest ranges, all the casual sets (group E). The anomalous positions of Irish archaeophytes and German natives (both in group C) explain the strong interactions found in the two-way ANOVA. As the order of countries is different in each status, it makes no sense to order the countries using all statuses which, statistically, is another factor in the interaction terms in the two-way ANOVA. 


\section{(B) Residence time effects}

The relationship of residence time to range size was studied in bivariate plots. Here we present the results just for naturalized neophytes; we also examined the effect in casuals and in total neophytes but such plots were uninformative. As can be seen in Figures 2 and 3, the relationship is fairly weak, so the first question is, is it straight or curved? That was examined with loess regressions, two results are shown in Fig. 2. In all areas, there is a slight indication of a flatter slope with the older dates. The majority of introductions, as can be seen, are in the $19^{\text {th }}$ and $20^{\text {th }}$ centuries, so the slopes for the older dates are based on fewer data. However, fitting ordinary least squares regressions to the data, before and after the most obvious break point, showed no significant change of slope, so we fitted one regression to the whole of each data set.

The lines for OLS regressions for the four areas are shown in Fig. 3. All the regressions are significant and the coefficients of determination $\left(\mathrm{r}^{2}\right)$ vary only from 3.1 to $13.2 \%$ (Table 4, which also gives the RMA slopes). Table 5 shows that the regression for Britain is significantly flatter than that of the others, which do not differ amongst themselves. It might be thought that the British result comes from the appreciable numbers of early introductions with small ranges, obvious in Fig. 3, but the loess results in Fig. 2A show that the British slope is flat up to the start of the $21^{\text {st }}$ century. The consensus, as far as that is possible with four data sets, is that $r^{2}$ is about $10 \%$ for naturalized neophytes in European countries, the median figure in our results.

A regression gives the best prediction from known data. However, in our data the uncertainties in the first record date are probably higher than those in range size. Range size is necessarily a minimum, some localities may have been missed. Date is usually also often regarded as the latest, leading to the phrase 'minimum residence time'. In many cases it may be too early, in that the date needed is the first date from which the species starts to spread. In the Czech flora (Williamson et al., 2005) over half the species with good statistical patterns of spread (28 out of 50) show a lag, 
determined rigorously (not from arithmetic plots) of from 7 to 154 years with a median of 41 years (Williamson, in press).

\section{(B) The time needed to complete spreading}

The second implication from the importance of residence time for range size is that it should be possible to estimate how long it takes, on average, for naturalized neophytes to complete their range, for mean range size to come to a maximum. If plots such as those in Fig. 2 showed an asymptote then an estimate would follow immediately, but in our data they do not. The mean range size will, however, not increase indefinitely but come to some maximum which will be higher than the present mean. There are several ways in which the maximum can be estimated.

A rather weak method is to compare the upper whiskers and particularly the uppermost points (extremes) for natives and naturalised neophytes in Fig. 1. These whiskers will contain fast spreading neophytes that have completed their spread. In all cases the neophytes are lower than the natives which suggests that the eventual mean for neophytes will be less than the native mean. The same conclusion comes from the British plants introduced before 1700. Britain is the only area with an appreciable number of such species (see Fig. 3). These will have been in Britain around 250 years longer than the median British established neophyte (from ca. 1650 to ca. 1900). Their mean abundance is $7.2 \%$ compared with (Table 3) $4.1 \%$ for all British naturalised neophytes and 8.4\% for British natives. As will be seen below, 250 years is possibly a mid to high estimate of the time to maximum range, so tentatively, the limiting mean range of British neophytes is unlikely to be larger than the mean range for natives and could be a touch smaller.

A different approach is to consider the range of habitats of the different statuses. This approach requires a translation from a habitat distribution to a mapping square distribution. Archaeophytes have rather special habitats, considered more fully in the Discussion, and that translates generally (Fig 1) into a higher median than for other groups but with a relatively short upper whisker. Neophytes are known to 
occupy a wider range of habitats, approximately those of natives, but with a different spectrum of abundances. Succinctly, neophytes are commoner in human affected and riparian habitats, natives in unproductive habitats. Crawley (1987), using 37 types of habitat, shows that difference from the percentage of alien species in different British habitats, though his figures include archaeophytes. Pyšek et al. (2005), for arable weeds in the Czech Republic, show that archaeophytes have the most distinct habitat requirements, while neophytes are close to, but different from, natives. It could be argued that, because of neophytes' high occupancy, like archaeophytes, of man modified habitats, that that would lead to a mean range size greater than natives. Or it could be argued that, because of their scarcity in widespread unproductive habitats, neophytes would be more restricted than natives. It is possible that the answer would be different in, say, Scotland with much mountainous habitat than in England with little. Many botanists, noting the ubiquity of ruderal vegetation, will probably prefer the first argument. Without the translation from habitats to mapping squares, it is not possible to decide which argument is right.

Taking all these arguments together, an assumption that neophytes will match natives will be near the truth and allows comparable estimates to be made across all four countries. With that assumption, it is possible to estimate the time to full range for neophytes by estimating the time for the mean neophyte range to match the mean native range.

In Table 6 there are eight estimates of the time needed to reach maximum mean naturalised neophyte range size. These are from four countries and two lines (OLS regressions and RMA). Six of the eight estimates cluster around 150 years, the other two, the British and Irish regression estimates, are around twice that. Note that the four RMA estimates agree much more closely than the regression ones. Tentatively, it seems that the time to maximum range in a European country-sized area may well be around 150 years but could be around twice that, 300 years or more.

\section{(A) DISCUSSION AND CONCLUSIONS}


The relative size of native and alien ranges from largest to smallest is (Table 3): archaeophytes (except in Ireland), natives, naturalized neophytes, casuals. Irish archaeophytes come between natives and neophytes. In that ordering, only the position of archaeophytes requires special explanation. Casual neophytes are very restricted in range in all four areas and are of course not spreading of their own accord. The difference between casual and naturalized means that data on these statuses should be kept separate. Naturalized neophytes have ranges more nearly matching those of natives but still significantly smaller in all cases, partly because they have mostly not yet filled their ranges.

Archaeophytes, many of which have been in western and central Europe for thousands of years, will be in equilibrium with their environment so might be expected to have the same range distribution as natives. That they have larger ranges, on average, is likely the result of their special habitat requirements. They are primarily arable weeds especially of warmer soils (Pyšek et al., 2005) and loess soils (Kühn et al., 2003). That also explains the anomalous ranges of Irish archaeophytes, as arable land is well known to be much more restricted in Ireland than in the other areas and loess is also scarce there.

A minor anomaly is that the mean range size (but not the maximum, Fig. 1) of German natives, measured as a proportion of the mapping units, is smaller than those of the other countries (Table 3). Germany has also the highest native species richness in our data (Table 1) and the largest area, stretching from the Alps to the North Sea, so there is greater opportunity for specialisation on local habitats (see also Korsch 1999).

As noted in the Introduction, residence time is an important determinant of range size. We found coefficients of determination ranging from 3.1 to $13.2 \%$. Among these, the flattest, British, slope is significantly different from the others. With four data sets, it is not possible to say if that is an anomaly or just part of the natural range of slopes. There are of course effects of country size, mapping unit size and the survey methods in all countries, but none of these seem likely to explain the effect, nor have we found any other plausible explanation, such as types of plants introduced, 
or variation in habitat heterogeneity, which seems comparable across all four areas. There are not enough such studies yet to do more than guess at the reason for these small $r^{2} s$, but we considered more species in more sampling units than any previous study.

Two implications of the importance of residence time were mentioned in the Introduction: the relative size of native and alien ranges, and the possibility of estimating the average time it takes an alien to fill its range. Our results for the first implication, discussed above, are somewhat more complicated than has been indicated before. On the second implication, our extensive data on range size and residence time mean we can estimate that, on average, naturalized alien plants (in areas varying from 80 to 360 thousand square kilometres) take at least 150 years to fill their range and possibly twice that, 300 years (Table 6). Similar numbers can be derived from Braithwaite et al. (2006): 313 years from the regression of 17-year range size change on residence time for neophytes recorded reliably in $2 \times 2 \mathrm{~km}$ squares, and 176 years for the median residence time of such neophytes showing no significant change of range size from 1987 to 2004 .

Although not helpful in managing individual species, both implications need to be allowed for in formulating policy. The importance of the second for policy, based on our results, is set out in Diversitas (2008). There is much variation in rates of spread, as shown by our small coefficients of determination, and the average time to fill a range is long. Rapid spreaders need to be identified quickly so that action can be taken against them. Plants introduced in the last century with smallish ranges and slow spread now may nevertheless, in time, become widespread and possibly troublesome species. The present distribution is not necessarily a guide to the future and monitoring programmes need funding alongside control programmes.

\section{(A) ACKNOWLEDGEMENTS}

IK, SK and PP acknowledge support from the DAISIE project SSPI-CT-2003511202, from the EU 6FP. PP was supported by institutional long-term research plans 
AV0Z60050516 (AS CR) and 0021620828(MŠMT CR, and by the Biodiversity Research Centre grant LC 06073 (MŠMT ČR). AM and JS were supported by the Irish Biochange project, funded by the Environmental Protection Agency as part of the ERTDI Programme, under the National Development Plan of the Irish Government. AM holds a postdoctoral research grant from the Fund for Scientific Research - Flanders.

\section{(A) REFERENCES}

Braithwaite, M.E., Ellis, R.W. \& Preston C.D. (2006) Change in the British flora 1987-2004. Botanical Society of the British Isles, London.

Cadotte, M.W., Murray, B.R. \& Lovett-Doust, J. (2006) Ecological patterns and biological invasions: using regional species inventories in macroecology. Biological Invasions 8, 809-821.

Castro, S.A., Figueroa, J.A., Muñoz-Schick, M. \& Jaksic, F.M. (2005) Minimum residence time, biogeographical origin, and life cycle as determinants of the geographical extent of naturalized plants in continental Chile. Diversity and Distributions 11, 183-191.

Clement, E.J. \& Foster, M.C. (1994) Alien plants of the British Isles. Botanical Society of the British Isles, London.

Crawley, M.J. (1987) What makes a community invasible? Symposia of the British Ecological Society 26, 429-453.

Diversitas (2008) Managing the global risks of invasive species. Submission by Diversitas/Global Invasive Species Program to the C[onvention on] $\mathrm{B}$ [iological] $\mathrm{D}$ [iversity] in depth review of invasive alien species. www.cbd.int Essl, F. (2007) From ornamental to detrimental? The incipient invasion of Central Europe by Paulownia tomentosa. Preslia 79, 377-389.

Gaston, K.J. (2003) The structure and dynamics of geographic ranges. Oxford University Press, Oxford. 
Guo, Q., Qian, H., Ricklefs, R.E. \& Xi, W. (2006) Distributions of exotic plants in eastern Asia and North America. Ecology Letters 9, 827-834.

Hamilton, M.A., Murray, B.R., Cadotte, M.W., Hose, G.C., Baker, A.C., Harris, C.J. \& Licari, D. (2005) Life-history correlates of plant invasiveness at regional and continental scales. Ecology Letters 8, 1066-1084.

Hejný, S. \& Slavík, B., eds. (1988-1992). Květena České republiky. Vol. 1 (1988), 2 (1990), 3 (1992). Academia, Praha.

Hill, M., Baker, R., Broad, G., Chandler, P.J., Copp, G.H., Ellis, J., Jones, D., Hoyland, C., Laing, I., Longshaw, M., Moore, N., Parrott, D., Pearman, D., Preston, C., Smith, R.M. \& Waters, R. (2005) Audit of non-native species in England, English Nature, Peterborough.

Klotz, S., Kühn, I. \& Durka, W. (2002) BIOLFLOR - Eine Datenbank mit biologischökologischen Merkmalen zur Flora von Deutschland. Schriftenreihe für Vegetationskunde 38, 1-334.

Korsch, H. (1999) Chorologisch-ökologische Auswertungen der Daten der floristischen Kartierung Deutschlands. Schriftenreihe für Vegetationskunde 30, 1-200.

Kubát, K., Hrouda, L., Chrtek, J. jun., Kaplan, Z., Kirschner, J. \& Štěpánek, J., eds. (2002) Klič ke květeně České republiky. Academia, Praha.

Kühn, I., Brandenburg, M. \& Klotz, S. (2004) Why do alien plant species that reproduce in natural habitats occur more frequently? Diversity and Distributions 10, 417-425.

Kühn, I., Brandl, R., May, R. \& Klotz, S. (2003) Plant distribution patterns in Germany - Will aliens match natives? Feddes Repertorium 114, 599-573.

Kühn, I. \& Klotz, S. (2003) The alien flora of Germany - basics from a new German database. Plant Invasions: ecological threats and management solutions (ed. by L.E. Child, J.H. Brock, G. Brundu, K. Prach, P. Pyšek, P.M. Wade \& M. Williamson) pp. 89-100. Backhuys, Leiden. 
Lambdon, P.W. \& Hulme, P.E. (2006) Predicting the invasion success of Mediterranean alien plants from their introduction characteristics. Ecography 29, 853-865.

Milbau, A., Stout, J.C. (2007) Database of alien plants in Ireland. Irish Biochange project, Dublin. http://www.biochange.ie/alienplants

NIST/SEMATECH (2006) e-Handbook of statistical methods. http://www.itl.nist.gov/div898/handbook/

Preston, C.D., Pearman, D.A. \& Dines, T.D. (2002) New atlas of the British and Irish Flora. Oxford University Press, Oxford.

Preston, C.D., Pearman, D.A. \& Hall, A.R. (2004) Archaeophytes in Britain. Botanical Journal of the Linnean Society 145, 257-294.

Pyšek, P. \& Jarošík, V. (2005) Residence time determines the distribution of alien plants. Invasive plants: ecological and agricultural aspects (ed. by Inderjit), pp. 77-96. Berkhäuser, Basel, Switzerland.

Pyšek, P., Jarošík, V., Chytrý, M., Kropáč, Z., Tichý, L. \& Wild, J. (2005) Alien plants in temperate weed communities: prehistoric and recent invaders occupy different habitats. Ecology 86, 772-785.

Pyšek, P. \& Richardson, D.M. (2007) Traits associated with invasiveness in alien plants: where do we stand? Biological invasions (ed. by W. Nentwig), pp. 97125. Ecological Studies 193, Springer-Verlag, Berlin.

Pyšek, P., Richardson, D.M., Rejmánek, M., Webster, G.L., Williamson, M. \& Kirschner, J. (2004) Alien plants in checklists and floras: towards better communication between taxonomists and ecologists. Taxon 53, 131-143.

Pyšek, P., Sádlo, J. \& Mandák, B. (2002) Catalogue of alien plants of the Czech Republic. Preslia 74, 97-186.

R Development Core Team (2006) R: A language and environment for statistical computing. R Foundation for Statistical Computing, Vienna, Austria. http://www.r-project.org

Rejmánek, M. (2000) Invasive plants: approaches and predictions. Austral Ecology 25, 497-506. 
Rejmánek, M., Richardson, D.M. \& Pyšek, P. (2005) Plant invasions and invasibility of plant communities. Vegetation ecology (ed. by E. van der Maarel), pp. 332355. Blackwell, Oxford.

Richardson, D.M. \& Pyšek, P. (2006) Plant invasions: merging the concepts of species invasiveness and community invasibility. Progress in Physical Geography 30, 409-431.

Schönfelder, P. (1999) Mapping the flora of Germany Acta Botanica Fennica 162, 4353.

Slavík, B. (1986-1990) Phytocartographical synthesis of the Czech Republic. Vol. 1 (1986), 2 (1990). Institute of Botany Průhonice. [In Czech]

Slavík, B. (1998) Phytocartographical synthesis of the Czech Republic. Vol. 3. Academia, Praha.

Slavík, B., ed. (1995-2004) Květena České republiky. Vol. 4 (1995), 5 (1997), 6 (2000), 7 (2004). Academia, Praha.

Sokal, R.R. \& Rohlf, F.J. (1995) Biometry: the principles and practice of statistics in biological research, 3 edn. Freeman, New York.

Williamson, M. (1998) Measuring the impact of plant invaders in Britain. Plant invasions: ecological mechanisms and human responses (ed. by U. Starfinger, K. Edwards, I. Kowarik \& M. Williamson), pp. 57-68. Backhuys, Leiden.

Williamson, M. (2002) Alien plants in the British Isles. Biological invasions: economic and environmental costs of alien plant, animal, and microbe species (ed. by D. Pimentel), pp. 91-112. CRC Press, Boca Raton.

Williamson, M. (in press) Variation in the rate and pattern of spread of introduced species and its implications. Bioinvasions and globalization. (ed. by $\mathrm{C}$. Perrings, H. Mooney \& M. Williamson). Oxford University Press, Oxford. Williamson, M. \& Gaston, K.J. (1999) A simple transformation for sets of range sizes. Ecography 22, 674-680.

Williamson, M., James, T. \& Pearman, D. (2006) Grid square nomenclature. BSBI News 103, 15-16. 
Williamson, M., Pyšek, P., Jarošík, V. \& Prach, K. (2005) On the rates and patterns of spread of alien plants in the Czech Republic, Britain and Ireland. Écoscience 12, 424-433.

Williamson, M., Stout, J., Dehnen-Schmutz, K., Milbau, A. and Hall, A. (in press) A provisional list of Irish archaeophytes. Irish Naturalists' Journal

Wilson, J.R.U., Richardson, D.M., Rouget, M., Procheş, S., Amis, M.A., Henderson, L. \& Thuiller, W. (2007) Residence time and potential range: crucial considerations in modelling plant invasions. Diversity and Distributions 13, 11-22.

Wu, S.-H., Chaw, S.-M. \& Rejmánek, M. (2003) Naturalized Fabaceae (Leguminosae) species in Taiwan: the first approximation. Botanical Bulletin of Academia Sinica 44, 59-66. 
Table 1 Number of native and alien species for which the data were available. 'Natives' are the total number of grid-mapped species.

'Archaeophytes' include a few casual species. 'dated' are the number of species with a first record date.

\begin{tabular}{|c|c|c|c|c|c|c|c|}
\hline & Natives & Archaeophytes & Natu & eophytes & Casuc & tes & All taxa \\
\hline & total & total & total & dated & total & dated & \\
\hline Ireland & 1027 & 95 & 254 & 254 & 259 & 259 & 1635 \\
\hline Britain & 1571 & 153 & 511 & 488 & 960 & 103 & 3195 \\
\hline Germany & 2550 & 251 & 388 & 136 & 139 & 23 & 3328 \\
\hline Czech Republic & 799 & 144 & 123 & 123 & 445 & 445 & 1511 \\
\hline
\end{tabular}


Table 2 Statistics of normality fits for logits. These are Ryan-Joiner statistics, equivalent to Shapiro-Wilks. In each cell the top figure is the correlation coefficient (of normit against logit value), the lower the probability of a good fit to a straight line. Probabilities in bold are not significant (the fit is good), the one in italics almost so. The effect of sample size on the probabilities is obvious, but it can also be seen that the correlation coefficient is $>0.99$ for all natives and all naturalized neophytes, except the (non-significant) correlation of Czech naturalized neophytes.

\begin{tabular}{|c|c|c|c|c|}
\hline \multirow[t]{2}{*}{ country/status } & native & archaeophyte & naturalized & casual \\
\hline & & & neophyte & neophyte \\
\hline \multirow[t]{2}{*}{ Ireland } & .9948 & .9940 & .9942 & .9763 \\
\hline & $<0.01$ & $>0.1$ & 0.0435 & $<0.01$ \\
\hline \multirow[t]{2}{*}{ Britain } & .9960 & .9796 & .9981 & 9838 \\
\hline & $<0.01$ & $<0.01$ & $>0.1$ & $<0.01$ \\
\hline \multirow[t]{2}{*}{ Germany } & .9928 & .9969 & .9922 & .9959 \\
\hline & $<0.01$ & $>0.1$ & $<0.01$ & $>0.1$ \\
\hline \multirow[t]{2}{*}{ Czech Republic } & .9941 & .9782 & .9894 & .9681 \\
\hline & $<0.01$ & $<0.01$ & 0.0519 & $<0.01$ \\
\hline
\end{tabular}


Table 3 Five groups found from a one-way ANOVA of 16 country-status sets (from 4 countries $\times 4$ statuses). The sets are listed in descending order of mean range size. Note that the order of countries is different in each status but the order of status is the same in all countries except for the inversion of Irish archaeophytes and natives. The mean percentage occupancy, from logits, is given for each set.

Group A: German archaeophytes 21.3, Czech archaeophytes 19.9, British archaeophytes 14.1.

Group B: $\quad$ Irish natives 11.5, Czech natives 11.1, British natives 8.4.

Group C: $\quad$ Irish archaeophytes 7.9, Czech naturalized neophytes 7.1, German natives 5.6, British naturalized neophytes 4.1.

Group D: $\quad$ Irish naturalized neophytes 2.0, German naturalized neophytes 1.8.

Group E: German casual neophytes 0.46, Irish casual neophytes 0.36 , Czech casual neophytes 0.33 , British casual neophytes 0.29 . 
Table 4 Results of linear (OLS) regression and reduced major axis (RMA) analyses of logit (naturalized species range) against first record date.

s.e.

intercept intercept s.e.

coefficient

r-square

Linear regression

Ireland

6.1758

1.6074

1.6501

$-0.0041$

0.0009

$<0.001$

0.083

Britain

9.3560

0.7598

$-0.0016$

0.0004

$<0.001$

0.031

Germany

13.1044

2.3881

$-0.0058$

0.0013

$<0.001$

0.132

Czech Republic

3.6167

$-0.0076$

0.0019

$<0.001$

0.113

Reduced major axis

$\begin{array}{lllll}\text { Ireland } & 25.6461 & 1.6501 & -0.0144 & 0.009 \\ \text { Britain } & 15.6228 & 0.7598 & -0.0091 & 0.0004 \\ \text { Germany } & 28.2384 & 2.3881 & -0.0159 & 0.0013 \\ \text { Czech Republic } & 41.1199 & 3.6167 & -0.0225 & 0.0019\end{array}$


Table 5 Probabilities of the post hoc multiple comparisons of the regressions in Table 4, from an ANCOVA analysis.

Ireland Britain Germany

Britain $\quad 0.0053$

$\begin{array}{lll}\text { Germany } & 0.15 & 0.000021\end{array}$

$\begin{array}{llll}\text { Czech Republic } & 0.20 & 0.000019 & 0.22\end{array}$ 
Table 6 Estimates of the time for the mean range size of naturalized neophytes to reach a maximum, from the OLS and RMA results in Table 4.

\begin{tabular}{llclr} 
& \multicolumn{2}{l}{ years from OLS } & years from \\
& regression & s.e. & RMA & s.e. \\
Ireland & 290 & 42.64 & 151 & 17.02 \\
Britain & 351 & 57.98 & 177 & 23.75 \\
Germany & 166 & 16.94 & 145 & 15.60 \\
Czech Republic & 160 & 14.02 & 141 & 12.26
\end{tabular}


Figure captions

Figure 1 Box and whisker plots, logit scale, of the range sizes, as a proportion of the total mapping units, of natives, archaeophytes, naturalized neophytes and casual neophytes.

Figure 2 Current range, logit scale, as a proportion of the total mapping units, of British (A) and Czech (B) naturalized neophytes against the first record date. Loess regression lines were fitted using a span of 0.9 .

Figure 3 Linear regressions of current range size on first record date of naturalized neophytes, for Ireland, Britain, Germany and the Czech Republic. Range sizes are expressed as the proportion of the total mapping units on a logit scale.

$\begin{array}{llr}\text { Czech Republic } & \text { dashed line } & \Delta \\ \text { Germany } & \text { dot-dash line } & + \\ \text { Ireland } & \text { dotted line } & \times \\ \text { Britain } & \text { solid line } & \circ\end{array}$


Ireland

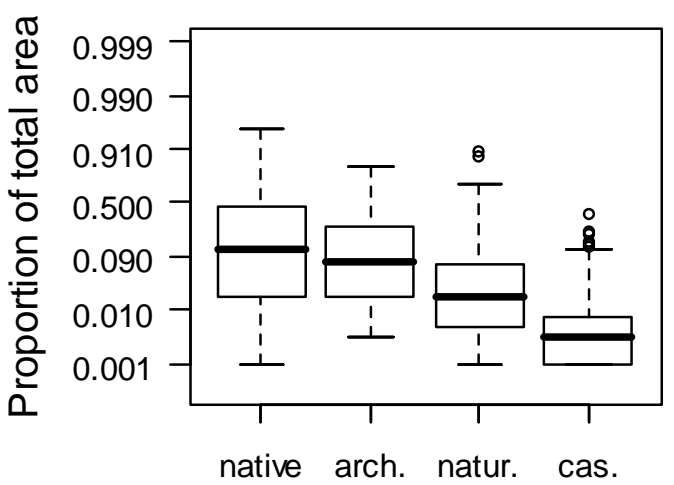

Germany

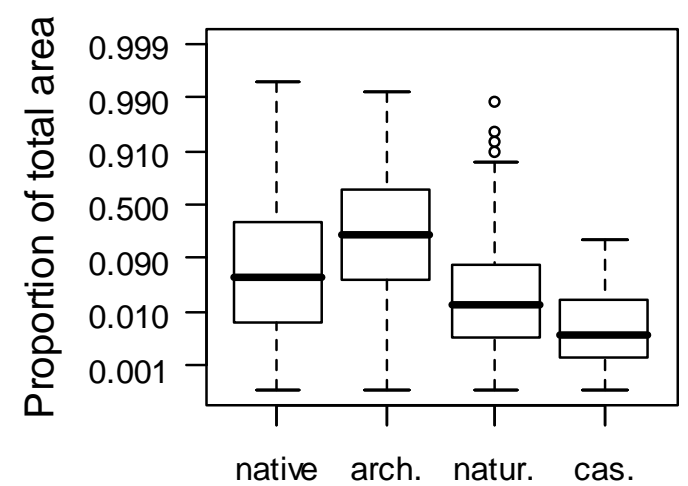

Britain

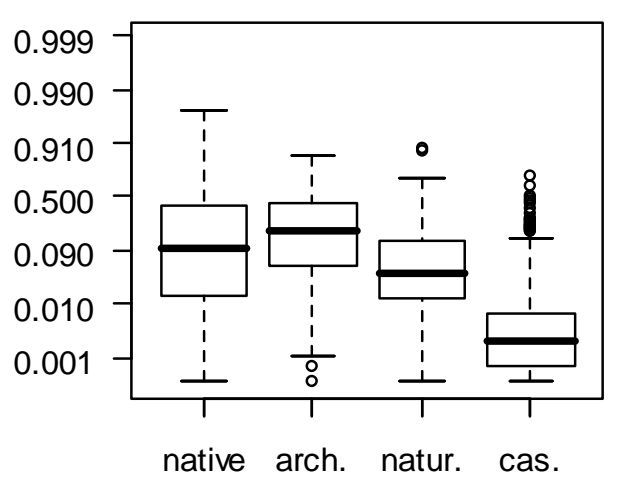

Czech Republic

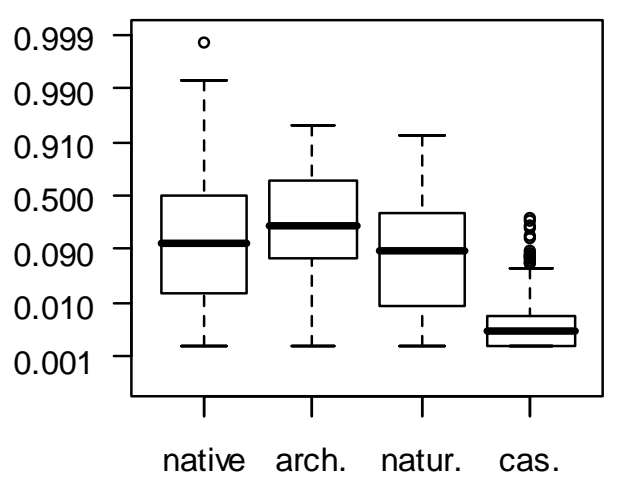

Figure 1 


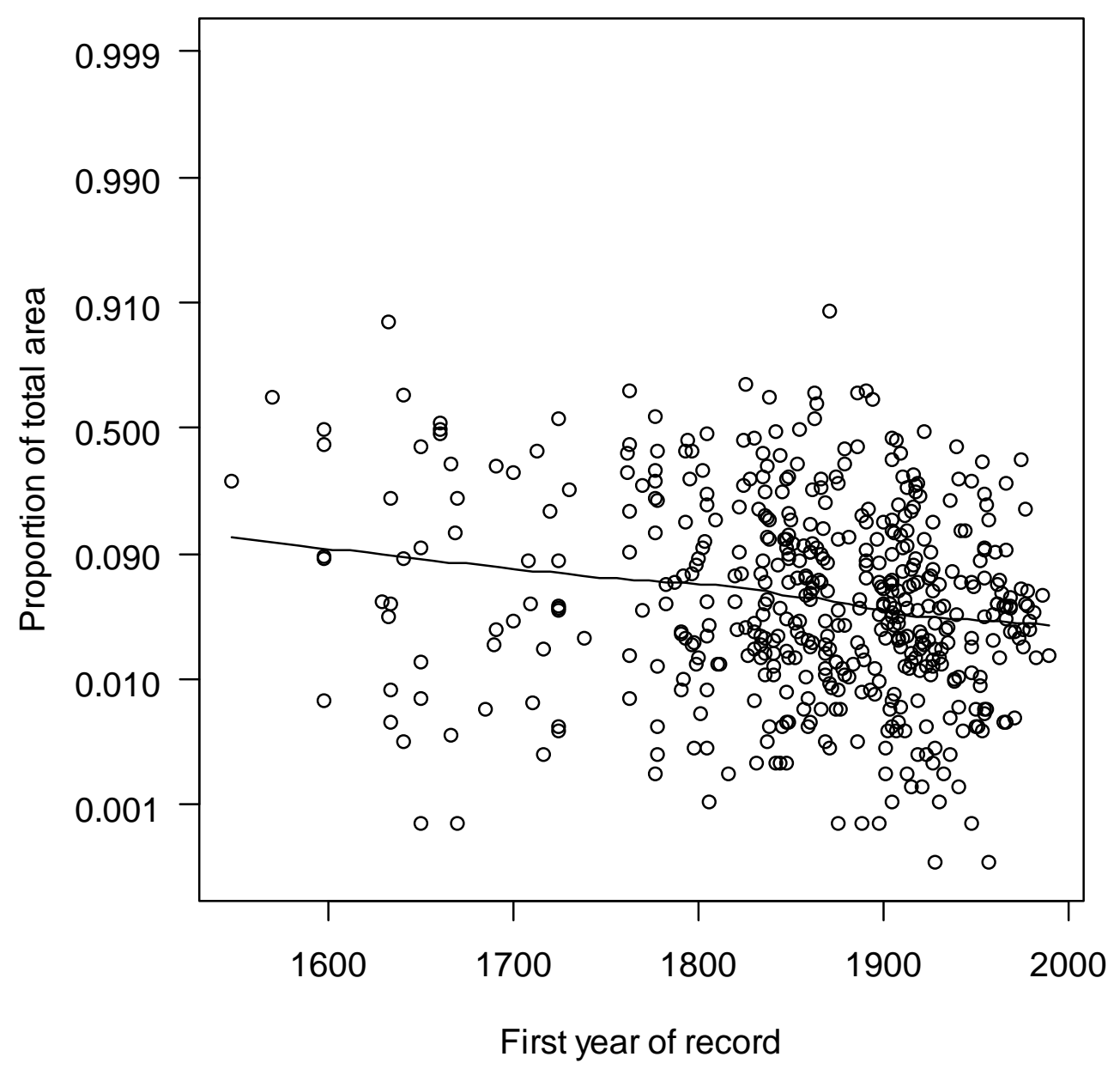

A 


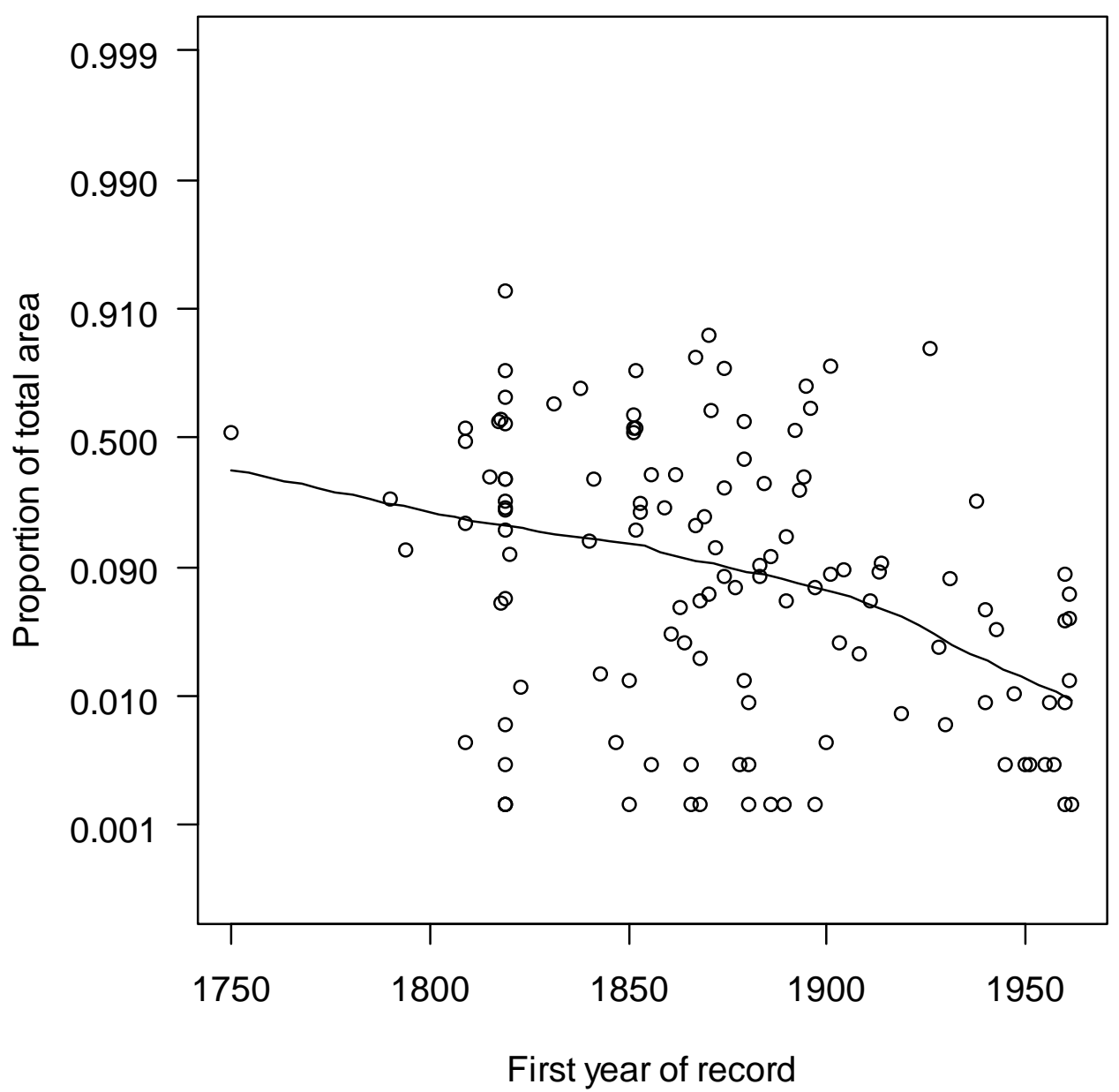

Figure 2 


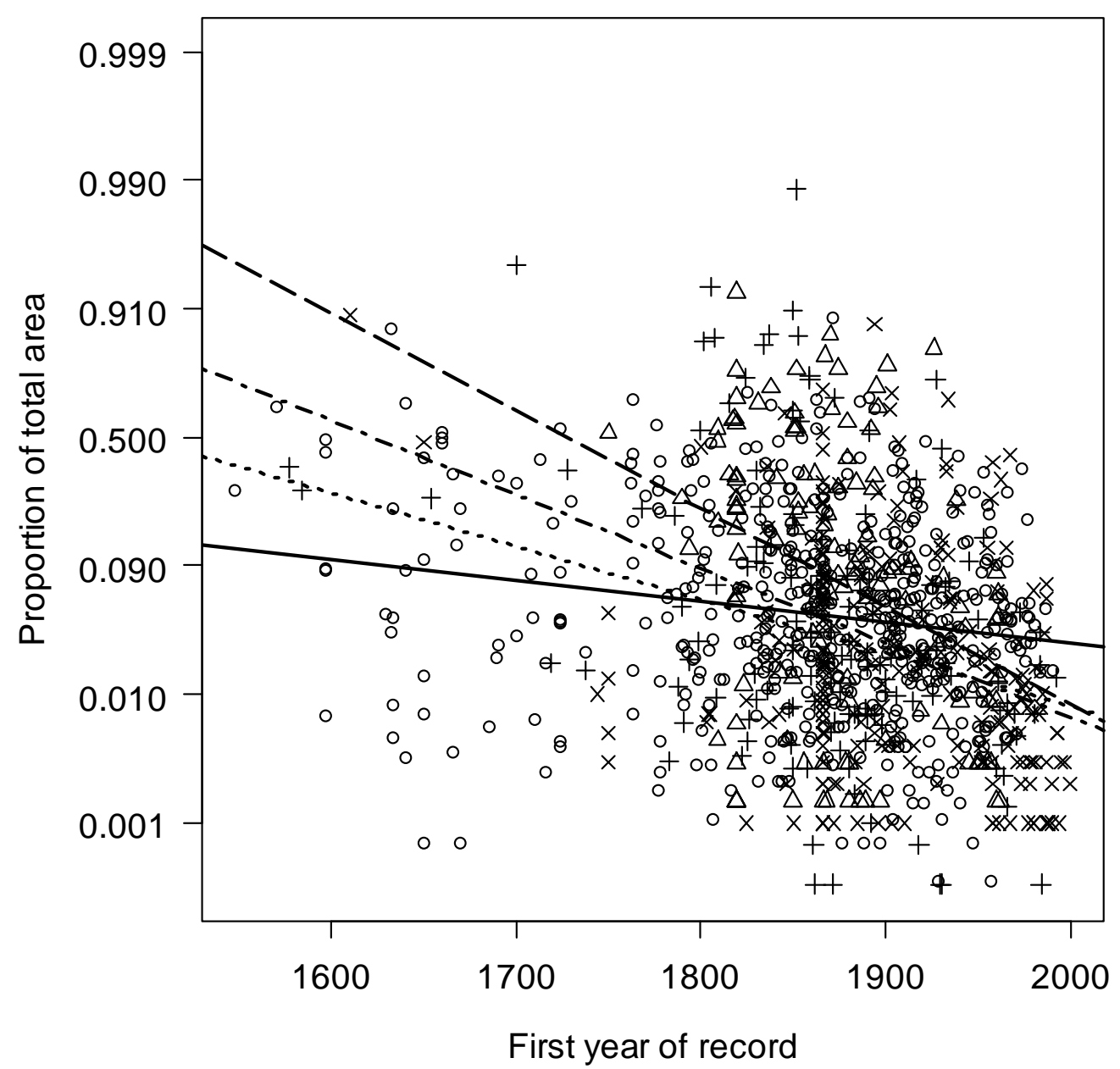

Figure 3 